Journal of Healthcare Technology and Medicine Vol. 5 No. 2 Oktober 2019

Universitas Ubudiyah Indonesia

e-ISSN : 2615-109X

\title{
HUBUNGAN PENGETAHUAN KADER DENGAN PELAKSANAAN POSYANDU BALITA DI WILAYAH KERJA PUSKESMAS MON GEUDONG KECAMATAN BANDA SAKTI KOTA LHOKSEUMAWE
}

\author{
Rika Mursyida*1, Mariani² \\ STIKes Bumi Persada Lhokseumawe \\ rikamursyida@ymail.com*11, mariani_ati@yahoo.com²
}

\begin{abstract}
ABSTRAK
Kegiatan penimbangan balita diposyandu menjadi salah satu indikator yang ditetapkan pada renstra kementerian kesehatan tahun 2010-2014. Indikator ini berkaitan dengan cakupan pelayanan kesehatan dasar khususnya imunisasi serta penanganan prevalensi gizi kurang pada balita. Tujuan penelitian ini untuk mengetahui hubungan pengetahuan kader dengan pelaksanaan posyandu balita di puskesmas Mon Geudong Kota Lhokseumawe maka dilakukannya penelitian ini. Penelitian ini bersifat observasional dengan pendekatan cross sectional. Populasi dalam penelitian ini seluruh kader di puskesmas Mon Geudong yang berjumlah 60 orang, sedangkan teknik pengambilan sampel adalah total populasi. Penelitian dilakukan dari tanggal 12 juni sampai 15 juni 2018. Analisa data digunakan uji chi square. Data dikumpulkan dengan membagikan kuesioner yang berisi 20 pertanyaan. Selanjutnya data diolah dengan bantuan sistem komputerisasi. Hasil penelitian pengetahuan kader berada pada kategori baik 38 responden $(63,3 \%)$, pelaksanaan posyandu berada pada kategori aktif 35 responden (58,3\%). Hasil didapati ada hubungan antara pengetahuan kader dengan pelaksanaan posyandu balita diwilayah kerja puskesmas Mon Geudong Kota Lhokseumawe menunjukkan bahwa analisa statistic menggunakan chi square test didapatkan $p$ value $=0,000$ yang berarti $p$ value $<\alpha$, yang berarti ada hubungan pengetahuan kader dengan pelaksanaan posyandu balita sehingga Ha diterima. Disarankan dapat menjadi masukan dan bagi para kader agar lebih aktif meningkatkan lagi pelaksanaan posyandu balita.
\end{abstract}

Kata Kunci: Pengetahuan kader, pelaksanaan posyandu balita

\begin{abstract}
The activity of weighing under five children in the integrated service post is one of the indicators set forth in the Ministry of Health strategic plan for 2010-2014. This indicator is related to the coverage of basic health services, especially immunizations and handling the prevalence of malnutrition in children under five. The purpose of this study was to determine the relationship of cadre knowledge with the implementation of a toddler integrated service post at the Mon Geudong Community Health Center in Lhokseumawe City. This research is observational with cross sectional approach. The population in this study were all cadres in the Mon Geudong community health center, amounting to 60 people, while the sampling technique was the total population. The study was conducted from 12 June to 15 June 2018. Data analysis used the chi square test. Data was collected by distributing questionnaires containing 20 questions. Then the data is processed with the help of a computerized system. The results of the cadre knowledge research were in the good category of 38 respondents (63.3\%), the implementation of integrated service posts was in the active category of 35 respondents (58.3\%). The results were found to be a relationship between cadre knowledge and implementation of integrated services for toddlers in the work area of the Mon Geudong community health center in Lhokseumawe City showed that statistical analysis using chi square test obtained $p$ value $=0,000$, which means $p$ value $<\alpha$, which means there is a
\end{abstract}


Journal of Healthcare Technology and Medicine Vol. 5 No. 2 Oktober 2019

Universitas Ubudiyah Indonesia

e-ISSN : 2615-109X

relationship between cadre knowledge and implementation integrated service post for toddlers so that $\mathrm{Ha}$ is accepted. It is suggested to be an input and for cadres to be more active in increasing the implementation of integrated services for toddlers.

Keywords: Cadre knowledge, implementation of toddlers posyandu

\section{LATAR BELAKANG}

Dari hasil Rikesdas tahun 2013 terdapat 280.225 posyandu pada tahun 2013 di Indonesia dari jumlah tersebut prosyandu pratama sebanyak $29,9 \%$ dan mandiri sebanyak $8,3 \%$. Dari hasil diatas diketahui proporsi tertinggi posyandu pratama dan proporsi terendah adalah posyandu mandiri dengan demikian diperlukan upaya intensif untuk meningkatkan jumlah posyandu mandiri (Riskesdas, 2013).

Berdasarkan data profil dinas kesehatan Profinsi Aceh pada tahun 2012, jumlah posyandu tahun 2010 sebanyak 6.652 unit yang terdiri dari 28,05\% posyandu purnama,dan 5,59 \% posyandu mandiri. Pada tahun 2011 sebanyak 6.894 unit yang terdiri dari 33,17\% posyandu purnama dan 6,44\% posyandu mandiri ,sedangkan pada tahun 2012 jumlah posyandu 6.995 unit dengan posyandu purnama sebanyak (37,78\% dan posyandu mandiri sebanyak 7,82\% dinas kesehatan provinsi aceh pada tahun 2012).

Data provinsi nanggroe aceh tahun 2015 jumlah AKB 12 per 1000 KH dan AKI 148,9 per 100.000 lahir hidup AKN sebanyak 8 per 1000 KH. Proporsi kematian ibu saat ini masih didominasi oleh kematian ibu nifas yaitu sebanyak 70 ibu (52\%), kematian ibu bersalin 34 ibu (25\%), dan kematian ibu dalam keadaan hamil 30 ibu (23\%)(profil kesehatan Prov. Aceh, 2015).

Posyandu merupakan salah satu bentuk usaha kesehatan bersumber daya masyarakat (UKBM) yang merupakan suatu bentuk pelayanan kesehatan di masyarakat di setiap kelurahan. Pada tahun 2016 tercatat 101 posyandu yang secara aktif memberikan pelayanan untuk balita dan lansia yang ada di Kota Lhokseumawe. dari jumlah tersebut $0 \%$ dalam katagori posyandu pratama, 9,9\% katagori posyandu madya, 89,1\% posyandu purnama, dan 1,0\% termasuk posyandu mandiri. (Dinkes Kota Lhokeseumawe, 2018).

Pada kegiatan posyandu, kader berperan mengembangkan wahana peran serta masyarakat juga memberdayakan segala fasilitas kesehatan yang tersedia, kenyataannya masih banyak fasilitas di objek penelitian baik tingkat primer ataupun tingkat rujukan yang kurang dimanfaatkan oleh kader ,yaitu pelaksanaan lima meja pada posyandu balita berupa memanfaatkan KMS sebagai alat bantu kesehatan secara optimal, pengisisan kohort, pencatatan imunisasi. Keadaan pemanfaatan fasilitas oleh kader di pengaruhi oleh beberapa faktor yang berhubungan dengan karakteristik individu diantaranya pendidikan, umur dan pekerjaan (Depkes RI, 2011). 
Journal of Healthcare Technology and Medicine Vol. 5 No. 2 Oktober 2019

Universitas Ubudiyah Indonesia

e-ISSN : 2615-109X

Pada pelaksanaan kegiatan di posyandu, kader merupakan penggerak utama kelancaran jalannya kegiatan ini. Untuk itu pengetahuan dan keterampilan yang benar dalam melakukan pelayanan seperti penimbangan, pemberian konseling/penyuluhan perlu mendapatkan bekal pengetahuan (fauzi, 2011).

Upaya meningkatkan fungsi dan kinerja posyandu menjadi kepedulian semua fihak, sehingga keberhasilan posyandu menjadi tanggug jawab bersama. Salah satu permasalahan posyandu yang paling mendasar adalah rendahnya tingkat pengetahuan kader baik dari sisi akademis maupun teknis. Kader adalah ujug tombak dari seluruh kegiatan yang dilaksanakan diposyandu. Keberadaan kader mejadi penting dan strategis, ketika pelayanan yang diberikan mendapat simpati dari masyarakat yang pada akhirnya akan memberikan masukan yang positif terhadap kepedulian dan partisipasi masyarakat (muflich, 2011).

Di wilayah UPTD Puskesmas Mon Geudong tahun 2016 diketahui sebanyak 60 orang kader tersebar di 12 pos Posyandu pada 6 desa. Pada kegiatan posyandu peran kader sebagai pencatatan dan pelaporan yang tidak terlepas dari peran petugas kesehatan. Sementara pada pelaksanaan posyandu masih ada kader yang kurang megerti tugas di masing-masig tahap yaitu meja I, II, III, dan IV, sehingga dari 12 posyandu yang dilaporkan masih ada posyandu yang belum tercapai target di atas $85 \%$ (Puskesmas Mon Geudong, 2018).

\section{DESAIN PENELITIAN}

Jenis penelitian yang digunakan bersifat observasional yang menggambarkan statistik suatu penelitian dan mencari hubungan yang positif antara variabel yaitu menganalisis hubugan pengetahuan kader dengan pelaksanaan posyandu balita. Pendekatan penelitian yang digunakan adalah desain cross sectional yaitu suatu penelitian dimana variabel independen dan dependen diukur secara bersamaan. Populasi dalam penelitian ini adalah semua kader posyandu yang ada di wilayah kerja puskesmas Mon Geudong Kota Lhokseumawe yang berjumlah 60 orang. Sedangkan sampel dalam penelitian ini adalah total populasi atau keseluruhan kader yang berjumlah 60 orang akan menjadi sampel.

\section{HASIL PENELITIAN DAN PEMBAHASAN}

Berdasarkan hasil yang didapat melalui peyebaran kuesioner pada 60 orang kader diwilayah kerja puskesmas Mo Geudong Kota Lhokseumawe tentang hubugan pengetahuan kader dengan pelaksanaan posyandu balita didapati hasil analisa: 
Journal of Healthcare Technology and Medicine Vol. 5 No. 2 Oktober 2019

Universitas Ubudiyah Indonesia

e-ISSN : 2615-109X

Tabel 5.2 Distribusi Frekwensi Pengetahuan Kader diwilayah Kerja Puskesmas Mon Geudog Kecamatan Banda Sakti Kota Lhokseumawe Tahun 2018

\begin{tabular}{c|c|c|c|}
\hline No & Pengetahuan & Jumlah & Persentase (\%) \\
\hline 1 & Baik & 38 & 63,3 \\
2 & Kurang & 22 & 36,7 \\
& Jumlah & 60 & 100 \\
\hline
\end{tabular}

Berdasarkan Tabel 5.2 dapat diketahui bahwa pengetahuan kader diwilayah kerja puskesmas Mon Geudong Kota Lhokseumawe sebagian besar berada pada kategori baik yaitu 38 orang (63,3\%)

Tabel 5.3 Distribusi Frekwensi Pelaksanaan Posyandu Balita diwilayah Kerja Puskesmas Mon Geudong Kecamatan Banda Sakti Kota Lhokseumawe Tahun 2018

\begin{tabular}{cccc}
\hline No & Pelayanan Posyandu & Jumlah & Persentase (\%) \\
\hline 1 & Aktif & 33 & 58,3 \\
2 & Tidak aktif & 25 & 41,7 \\
& Jumlah & 60 & 100 \\
\hline
\end{tabular}

Berdasarkan Tabel 5.3 dapat diketahui bahwa pelaksanaan posyandu balita diwilayah kerja puskesmas Mon Geudong Kota Lhokseumawe sebagian besar berada pada kategori aktif yaitu 35 orang (58,3\%)

Analisa Bivariat

Tabel 5.4 Hubungan Pengetahuan Kader dengan Pelaksanaan Posyandu Balita diwilayah Kerja Puskesmas Mon Geudong Kecamatan Banda Sakti Kota Lhokseumawe Tahun 2018

\begin{tabular}{|c|c|c|c|c|c|c|c|c|}
\hline \multirow{3}{*}{$\begin{array}{l}\text { Pengetahuan } \\
\text { kader }\end{array}$} & \multicolumn{4}{|c|}{ Pelaksanaan Posyandu } & \multirow{2}{*}{\multicolumn{2}{|c|}{ Jumlah }} & \multirow[t]{3}{*}{$\alpha$} & \multirow[t]{3}{*}{$P$} \\
\hline & \multicolumn{2}{|c|}{ Aktif } & \multicolumn{2}{|c|}{$\begin{array}{c}\text { Tidak } \\
\text { aktif }\end{array}$} & & & & \\
\hline & $\mathrm{F}$ & $\%$ & $f$ & $\%$ & $\mathrm{~F}$ & $\%$ & & \\
\hline Baik & 35 & 58,3 & 3 & 5,0 & 38 & 63,3 & & \\
\hline Kurang & 3 & 5,0 & 19 & 31,7 & 22 & 36,7 & & \\
\hline Total & 38 & 63,3 & 21 & 36,7 & 60 & 100 & 0.05 & 0,000 \\
\hline
\end{tabular}

Berdasarkan Tabel 5.4 tentang hubungan pengetahuan kader dengan pelaksanaan posyandu balita diwilayah kerja puskesmas Mon Geudong Kota Lhokseumawe menujukkan hasil analisa statistik menggunakan chio-square test didapatkan $p$ value $=0,000$ yang berarti $p<\alpha$, yang berarti ada hubungan pengetahuan kader dengan pelaksanaan posyadu balita diwilayah kerja puskesmas Mon Geudong Kecamatan Banda Sakti Kota Lhokseumawe 
Journal of Healthcare Technology and Medicine Vol. 5 No. 2 Oktober 2019

Universitas Ubudiyah Indonesia

e-ISSN : 2615-109X

Hasil dan Pembahasan

Berdasarkan hasil penelitian yang dilakukan pada tanggal 12 juni 2017 sampai 15 juni 2018 terdapat 60 orang kader di wilayah kerja puskesmas Mon Geudong Kota Lhokseumawe diperoleh hasil analisa uji chi-square menujukkan ada hubungan pengetahuan kader dengan pelaksanaan posyandu balita di wilayah kerja puskesmas mon geudong kecamatan banda sakti kota lhokseumawe didapati ada hubungan yang mana pengetahuan kader sangat berhubungan dengan posyadu balita.

Analisa univariat

a. Pengetahuan kader

Berdasarkan tabel 5.2 dapat diketahui bahwa pengetahuan kader diwilayah kerja puskesmas Mon Geudong Kota Lhokseumawe sebagian besar berada pada kategori baik yaitu 38 orang (63,3\%) Asumsi penulis hal ini terjadi karena rata-rata umur responden berada pada 20 sampai 300 tahun sebanyak 25 orang dan pendidikan responden berada pada SMA yaitu sebanyak 34 orang. Hasil penelitian ini sejalan dengan penelitian latif (2010) berdasarkan analisis multivariat ternyata variabel yang berhubungan bermakna degan praktek kader dalam pelaksanaan posyandu adalah variabel pengetahuan. Hasil analisis didapatakan pengetahuan sebesar 3615 , sehingga dapat diartikan bahwa kader posyandu yang memiliki peegtahuan baik memiliki kemungkinan berpraktik 3 kali lebih baik dalam pelaksanaan posyandu dibandingkan dengan kader posyandu yang memiliki pengetahuan kurang baik tentang pengertian, sasaran, kegiatan posyandu dan tugas kader.

Hasil ini seusai dengan teori L.Green dalam notoadmodjo (2010), yang menyatakan perubahan perilaku seseoarang dipegaruhi oleh faktor predisposi yaitu faktor yang mempermudah seseorang atau masyarakat berperilaku (dalam hal ini adalah pengetahuan kader tentang pengertian, sasaran, kegiatan, tugas, fungsi dan syarat menjadi kader dan sikap kader terhadap tugas-tugas kader), reinforcing faktor yaitu faktor yang memperkuat dan mendukung seseorang atau masyarakat berperilaku (dalam hal ini adalah dukungan yang diberikan oleh petugas kesehatan).

Hal ini berkaitan degan pernyataan (fauzi,2011) pada pelaksanaan kegiatan di posyandu, kader merupakan penggerak utama kelancaran jalannya kegiatan ini. Untuk itu pengetahuan dan keterampilan yang benar dalam melakukan pelayanan seperti penimbagan, pemberian konseling / penyuluhan perlu mendapat bekal pengetahuan.

b. pelaksanaan posyandu

berdasarkan table 5.3 dapat diketahui bahwa pelaksanaan posyandu balita diwilayah kerja puskesmas Mon Geudong Kota Lhokseumawe sebagian besar berada pada kategori aktif yaitu 35 orang $(58,3 \%)$ asumsi penulis hal ini terjadi karena rata-rata pekerjaan responden adalah IRT yaitu 
Journal of Healthcare Technology and Medicine Vol. 5 No. 2 Oktober 2019

Universitas Ubudiyah Indonesia

e-ISSN : 2615-109X

sebayak 32 orang. Kalau pelaksanaan posyandu balita aktif maka hal ini rata-rata kader dapat melaksanakan posyandu pada setiap bulan karena kader tidak melaksanakan pekerjaan yang lain, sehingga kader bias lebih aktif dalam mealkukan kegiatan posyandu.

Hasil penelitian ini sejalan degan penelitian paramita (2012), didapatkan sebagian besar pelaksanaan posyadu oleh kader tidak lengkap sebayak 33 respoden $(66,0 \%)$, sehingga yang lengkap sebanyak 17 responden (34,0\%). Pemanfaatan pelayanan kesehatan diposyandu oleh masyarakat sangat ditentukan oleh pera kader sebagai penggerak yang mendapatkan dukungan dari tokoh masyarakat (TOMA) dan petugas kesehatan. Hal tersebut dikarenakan salah satu tugas utama kader adalah menggerakkan masyarakat untuk dating ke posyandu. Dukungan tokoh masyarakat (kepala desa) kepada kader posyandu sangat penting hal ii disebabkan karena tokoh masyarakat tersebut merupakan tokoh yang paling disegani dan yang paling berpengaruh diwilayah tersebut. Dukungan dan anjuran dari tokoh masyarakat merupakan salah satu bentuk motivasi dan semangat bagi kader posyandu dalam menjalankan tugasnya dalam kegiatan posyandu (sucipto,2010). Kader adalah ujung tombak dari seluruh kegiatan yang dialaksaakan diposyandu. Keberadaan kader menjadi penting dan strategis, ketika pelayanan yang diberikan mendapat simpati dari masyarakat yang pada akhirnya akan memberikan masukan yang positif terhadapat kepedulian dan partisipasi masyarakat (muflich, 2011).

Analisa bivariat

a. Hubungan pengetahuan kader dengan pelaksanaan posyandu balita

Berdasarkan table 5.4 tentang hubungan pengetahuan kader dengan pelaksanaan posyandu balita diwilayah kerja puskesmas Mon Geudong Kota Lhokseumawe menujukkan hasil analisa statistik menggunakan chio-square test didapatkan $p$ value $=0,000$ yang berarti $p<\alpha$, yang berarti ada hubungan pengetahuan kader dengan pelaksanaan posyadu balita diwilayah kerja puskesmas Mo Geudong Kecamatan Banda Sakti Kota Lhokseumawe

Asumsi penulis hal ini terjadi karena rata-rata pengetahuan kader baik, sehingga kader dalam hal ini mengetahui $(\mathrm{Cl})$ apa yang menjadi tanggung jawabnya didalam pelaksanaan dan pelaporan hasil posyandu yang harus dilakukan sebagai kader. Dalm hal ini juga sangat dipengaruhi oleh pekerjaan kader rata-rata sebagai ibu rumah tangga, akan lebih banyak waktu dalam melaksanakan tugas sebagai kader. Hasil penelitian ini sejalan dengan penelitian Mubarak (2010), yaitu umur, pendidikan, pekerjaan, minat, pengalaman, kebudayaan lingkungan sekitar dan informasi. Hal ii berkaitan dengan penelitian agustina rostita (2012) dengan judul faktor-faktor yang berhubungan dengan ketrampilan kader dalam menginterprestasikan hasil penimbangan ( $\mathrm{N}$ dan $\mathrm{T}$ ) dalam KMS di 
Journal of Healthcare Technology and Medicine Vol. 5 No. 2 Oktober 2019

Universitas Ubudiyah Indonesia

e-ISSN : 2615-109X

puskesmas Baumata kabupaten kupang. Jenis penelitian adalah deskriptif analitik populasi penelitian adalah kader posyandu di Baumata kabupateng kupang. Jumlah 49 responden dengan model teknik random sampling alat pengumpulan data meggunakan format kuesioner berdasarkan analisis korelasi person menunjukkan ada hubungan yang bermakna antara pengetahuan kader, pendidikan kader dengan interprestasi hasil penimbangan ( $\mathrm{N}$ dan $\mathrm{T}$ ) dan menggambar grafik pertumbuhan anak (nilai $p<0,05$ ). Tidak ada hubugan yang bermakna antara pelatihan kader, keaktifan kader dengan interprestasi hasil penimbangan ( $\mathrm{N}$ dan $\mathrm{T}$ ) ditujukkan dengan $p>0,05$, dan ada hubungan yang bermakna antara keaktifan kader degan menggambar grafik pertumbuhan anak (nilai $p<0,05$ ). Kesimpulan: ad hubugan yang bermakna antara pengetahuan kader, pendidikan kader dengan keteramplian menginterprestasikan hasil penimbangan ( $\mathrm{N}$ dan $\mathrm{T}$ ) dan menggambar grafik pertumbuhan anak, dan tidak ada hubungan yang bermakna antara pelatihan kader, keaktifan kader dengan menginterprestasikan hasil penimbangan ( $\mathrm{N}$ dan $\mathrm{T}$ ), serta ad hubungan yag bermakna antara keaktifan kader dengan meggambar grafik pertumbuhan anak.

\section{KETERBATASAN PENELITIAN}

1. Penelitian ini memiliki keterbatasan dalam pengambilan sampel yang hanya diambil pada posyandu di wilayah kerja puskesmas Mon Geudong saja, sedangkan pada puskesmas lain tidak.

2. Sampel dalam penelitian ini berjumlah hanya 60 responden saja, sehingga jumlah reponden dibawah 100 mengakibatkan hasil analisis kurang stabil.

3. Penelitian ini merupakan penelitian observasional dengan pendekatan cross sectional dimana pengambilan data haya dilakukan satu kali secara bersamaan. Oleh sebab itu oeelitian ini tidak bermaksud melihat hubungan sebab akibat antara variabel independen dengan variabel dependen hanya memeberikan informasi tentang hubungan antara variabel dependen, dengan variabel independen.

\section{KESIMPULAN}

Berdasarkan hasil penelitian yang didapatkan maka dapat ditarik beberapa kesimpulan antara lain adalah:

1. Pengetahuan kader diwilayah kerja puskesmas Mon Geudong Kecamatan Banda sakti Kota Lhokseumawe Tahun 2018 sebagian besar berada pada katagori Baik.

2. Pelaksanaan posyandu balita di wilayah puskesmas Mon Geudong Kecamatan Banda sakti Kota Lhokseumawe Tahun 2018 sebagian besar berada pada katagori Aktif. 
Journal of Healthcare Technology and Medicine Vol. 5 No. 2 Oktober 2019

Universitas Ubudiyah Indonesia

e-ISSN : 2615-109X

3. Hubungan pengetahuan kader dengan pelaksanaan posyandu balita di wilayah kerja puskesmas Mon Geudong Kecamatan Banda sakti Kota Lhokseumawe Tahun 2018 menujukkan bahwa hasil analisa statistik menggunakan chi-square test didapatkan $p$ value $=0,000$ yang berarti $p<\alpha$, yang berarti ada hubungan pengetahuan kader dengan pelaksanaan posyandu balita di wilayah kerja mon geudong kecamatan Banda Sakti Kota Lhokseumawe.

\section{SARAN}

1. Responden

Diharapkan dapat menjadi masukan dan bagi para kader agar lebih aktif dalam meningkatkan pelaksanaan posyandu balita.

2. Bagi institusi pendidikan

Diharapkan penelitian ini dapat menambah literatur dan kaedah penelitian bagi peserta didik STIKes Bumi Persada Lhokseumawe.

3. Bagi peneliti selanjutnya

Diharapkan penelitian ini dapat dilanjutkan lagi dalam metode penelitian yang lebih kompleks dan rinci tentang pengetahuan kader dan pelaksanaan posyandu.

\section{DAFTAR PUSTAKA}

Agung (2010) Peran Kader Posyandu Dalam Pencegahan Diare.Eprints.undip.ac.id/43819/1/08_PRATIWI. Pdf. (diakses 25 juli 2017)

Arikunto, S (2006). Prosedur Penelitian Suatu Pendekatan Praktek. Jakarta:Rieka Cipta.

Budiarto, (2004). Perilaku, pengantar Ilmu Perilaku Kesehatan dan Pedidikan Kesehatan. Jakarta : EGC

Depkes (2011) Buku Panduan Kader Posyandu menuju Keluarga Sadar Gizi. Jakarta (2012) Buku Keseshatan Ibu dan Anak. Jakarta.

(2013) Pengembangan Kesehatan Meuju Indonesia. Jakarta.

Dinkes Aceh (2015) Profil Kesehatan Provinsi Aceh. Dinkes.acehprov.go.id/uploads/fulltext_prof2016pdf (diakses 25 juli 2017).

(2012) Profil Kesehatan Provinsi Aceh. Dinkes.acehprov.go.id/uploads/fulltext_prof2016pdf (diakses 25 juli 2017).

Dinas kesehatan Kota Lhokseumawe (2018). Kesga Program Posyandu Lhokseumawe.

Erfandi (2009) Promosi Kesehatan Teori dan Aplikasi, Jakarta: PT Rineka Cipta.

FKM (2007) Posyandu dan Kader Kesehatan. Jurnal.usu.id/jurnal/index.php/preventif/article/.../5751 /4517jurnaluntad.ac.id/jurnal/index.php/preventif/article/.../5751/4517eprints.uny.ac.id/17505 /1/SKRIPSI\%20KOMPLIT.pdfskripsi komplit pdf prints. ums.ac.id/66430/1/j210050078.pdf. (diakses 29 juni 2017)

Fauzi (2011). Buku Panduan Kader Posyandu Meuju Keluarga Sehat. Yogyakarta

Kemenkes RI. (2011) Pedoman Pelaksanaan Stimulasi Deteksi dan Intervensi Dini Tumbuh Kembang Anak Ditingkat Pelayanan Kesehatan Dasar. Jakarta. 
Journal of Healthcare Technology and Medicine Vol. 5 No. 2 Oktober 2019

Universitas Ubudiyah Indonesia

e-ISSN : 2615-109X

Latif (2010) Hubugan Faktor predisposisi Kader (Pengetahuan dan Sikap Kader Terhadap Posyandu) dengan Praktik Kader dalam Pelaksanaan Posyandu, internet, tersedia dalam: portalgaruda.org/article.php?article=21054\&val=1321 (Diakses 20 Juli 2017)

Wahyutomo (2010) kuesioner penelitian hubungan karakteristik dan peran kader posyandu degan pemantauan tumbuh kembang balita di puskesmas katalidu bojonegoro. Digilib.uns.ac.id (diakses 12 april 2017) (2012). Panduan kader posyandu menuju keluarga sadar gizi.jakarta.

Notoadmodjo(2010) promosi kesehatan teori dan aplikasi. Jakarta: PT rineka cipta

Paramita(2012) Hubungan karakteristik kader dengan pelaksanaan posyandu balita perpusnwu.web.id/ karyailmiah/documents/33.pdf.internet.

Widiastuti (2012) Dasar-dasar metodologi penelitian kedokteran da kesehatan. Raja grafindo. jakarta 